\author{
ROSA MARÍA AVENDAÑO* \\ JOSÉA. MORENO MENA** \\ ENRIQUE PRIEGO MENDOZA**
}

\title{
LAS ONG EN LA FRONTERA BAJA CALIFORNIA-CALIFORNIA: UN ACERCAMIENTO AL ESTUDIO DE LA DIPLOMACIA CIUDADANA
}

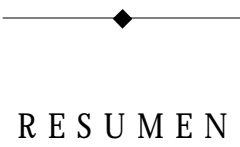

En la región fronteriza California-Baja California, zona de grandes interacciones transfronterizas, las ong de apoyo a los migrantes de Estados Unidos y México, en los últimos años han presentado una serie de respuestas ante las políticas antiinmigrantes del gobierno estadounidense, al gunas delas cuales rebasan el control de las esferas gubernamentales para transformarseen una especie de diplomacia ciudadana que trata de influir en las políticas públicas y las agendas de discusión sobre relaciones exteriores de ambos países. En ese proceso han construido estrategias comunes y redes coyunturales de manera informal, que inauguran nue vas formas de participación ciudadana. Este trabajo tieneel propósito de describir precisamente esas respuestas organizadas.

\section{A B STRA C T}

During recent years, the non-governmental organizarions (NGO) supportive of migrants from the United States and Mexico along the California-Baja California border region, a zone of great trans-border interactions, have presented a series of responses before the anti-migration policies of the A merican government, some of which go beyond thegovernmental spheres. They havenow transformed themselves into a sort of citizen diplomacy, which seeks to influence the public policies and discussion agendas on foreign relations of both countries. Common strategies and circumstantial networks have been created along the lines of this process in a somewhat informal way, which inaugurate new ways of citizen participation. It is precisely the purpose of this article to describe such organized responses.

\footnotetext{
* Maestra en desarRollo regional.

**INVESTIGADORES DEL INSTITUTO DE INVESTIGACIONES SOCIALES DE LA UNIVERSIDAD AUTÓNOMA DE BAJA CALIFORNIA. Correos electrónicos: jmoreno@faro.ens.uabc.mx y epriego@faro.ens.uabc.mx
} 


\section{INTRODUCCIÓN}

En losúltimos años, las organizaciones no gubernamentales(ONG) que desarrollan actividades deapoyo, asistencia, asesoría y defensa delos migrantes indocumentados, están desempeñando un papel cada vez más importante, en la definición de la agenda de política exterior de nuestro país en materia de migración. Han construido estrategias comunes y redes informales para presentar sus propuestas y llevar la problemática de los trabajad ores migrantes a foros internacionales de discusión gubernamental. Han desarrollado diversas actividades con la intención de influir en las agendas y acuerdos de los gobiernos involucrados, inaugurando con ello formas incipientes de diplomacia ciudadana. Sus acciones se presentan paral el amentea la participación de las instituciones gubernamentales, en donde no necesariamente coinciden con sus propuestas.

De igual manera, la participación de las ONG, cada vez más, tiene una relación directa con el papel que juegan en las problemáticas domésticas, en donde sus intervenciones adquieren una creciente influencia en aspectos de política pública.

Este tipo deprácticas - cuyo referenteson al gunas experiencias en la discusión deotras problemáticas como el medio ambiente, la política de población, los problemas de la mujer, y los derechos humanos en general, etcétera - comienzan también a manifestarse en las ONG de Baja California. Especialmente las organizaciones que desarrollan al gunas actividades deasistencial ismo y apoyo a migrantes en la región fronteriza de Baja Cal ifornia y el suroestedeEstados Unidos, empiezan ya a integrarse a redes y coaliciones nacionales, regionales, locales y transfronterizas, para la defensa de los migrantes indocumentados, y a buscar foros externos en donde plantear sus demandas y propuestas.

En este trabajo, en primer término se aborda la importancia que están teniendo las ONG como nuevos actores en la esfera nacional e internacional, y en segundo, sediscuteel concepto de diplomacia ciudadana.

En un segundo apartado, se describe la construcción de redes informales para la defensa delos migrantes internacionales; sesugiere 
que esas iniciativas son formas incipientes de diplomacia ciudadana que tienden a influir en la agenda de discusión internacional sobre estaproblemática.

En el tercer apartado, se reseñan al gunas respuestas organizadas de las ONG de Baja California ante las medidas antiinmigrantes Ley 187 y la Operación Guardián, como un ejemplo de constatación empírica de los procesos de diplomacia ciudadana desde la frontera norte. Se rescatan, además, al gunas experiencias locales de redes y coaliciones para la defensa de los trabajadores migratorios. Final mente, se anal iza la participación ciudadana organizada de Baja California, como partedeun proceso deregional ismo transfronterizo.

Separtedel supuesto de quees en el ámbito dela política migratoria, más que en cualquier otro asunto local, donde las organizaciones ciudadanas deBaja California tienen mayores posibilidades de influir, tanto en la agenda de las relaciones exteriores como en las políticas públicas domésticas, debido fundamental mentea queseconsidera que la migración indocumentada es uno de los puntos neurál gicos de la relación México-Estados Unidos. A unado a ello, está el hecho de que en este estado fronterizo se registra uno de los mayores flujos migratorios hacia Estados Unidos, por lo cual, las ONG quedefienden a los trabajadores migrantes presentan una mayor madurez que les permite pasar de una posición de asistencialismo y/ o contestataria a otra decarácter propositiva, que ofrece alternativas.

Paradescribir las experiencias decoordinación delas ONG recurrimos a utilizar fuentes hemerográficas, documentos inéditos y algunas entrevistas, puesto que son las únicas evidencias sobre la temática; asimismo, utilizamos algunas fuentes bibliográficas para sustentar nuestro análisis. ${ }^{1}$

${ }^{1}$ Los estudios regionales de las ONG están aún en proceso, no hay una vasta bibliografía que nos permita caracterizar o definir un perfil completo sobre ellas; 


\section{DEFINIENDO LASESCALASDE PARTICIPACIÓN DE LASONG}

En fechas recientes, un nuevo actor social comienza a tener un papel importante en los asuntos de la vida pública de todo el mundo. Nos referimos a los grupos organizados de la sociedad civil que se reúnen para responder a problemáticas concretas, a los cual es comúnmentese les ha denominado organismos civiles u organizaciones no gubernamentales (ONG). ${ }^{2}$ La influencia de estos grupos trasciende, incluso, las fronteras nacionales para convertirse en un nuevo interlocutor de la ciudadanía, especial mente de aquélla que no tiene manera de hacerse escuchar. ${ }^{3}$

Quienes han estudiado a las ONG encuentran dificultades para definirlas, debido, entre otras razones, a su heterogeneidad, su diversidad detemáticas y a los actores a quienes se dirigen, así como a las estrategias de acción que siguen y las fuentes de donde obtienen su financiamiento. Algunos autores consideran que el término es bastantereducido y no da cuenta dela abundancia deopciones, por lo cual prefieren distinguirlas como: organizaciones no gubernamentales para el desarrollo (ONGD); organizaciones autónomas de promoción social y desarrollo (OAPSD) o simplementeorganizaciones civiles. ${ }^{4}$

\footnotetext{
sin embargo, hay al gunas aproximaciones que pueden consultarse. Al respecto, véase Moreno Mena, José "Las organizaciones no gubernamentales: un interlocutor dela sociedad civil" (1996b); Rosa María Avendaño, "Las ONG en Baja California: un acercamiento al trabajo que realizan (1996); Sergio Hernández, "Los efectos de la globalización en los partidos políticos y en los procesos electorales locales" (1996). ${ }^{2}$ Incluso instituciones internacionales como el Banco Mundial, reivindican a este tipo de organizaciones como una fuerza importante a considerar en las nuevas estrategias de desarrollo, especialmente por sus aportes a los niveles micro (Cortez, 1994:152).

${ }^{3}$ Según Paul Ghils (1992:446) actualmente existen 23000 oNG en todos los continentes.

${ }^{4}$ Para una discusión sobre lo que son las ONG, sus características y antecedentes, remítasea Foro de A poyo Mutuo, O rganismos no gubernamentales. D efinición, presencia y perspectivas (1995).
} 
Para efectos de este trabajo, y sin pretender agotar esa discusión, concebimos a las organizaciones no gubernamental es como los grupos dela sociedad civil quetienen como objetivo fundamental beneficiar a terceros, que desarrollan sus actividades sin fines de lucro y no dependen para su sobrevivencia de instancias de gobierno o partidos políticos, sino de otras fuentes de financiamiento originadas en fundaciones nacionales o internacionales. Pueden tener registro jurídico como asociaciones civiles, instituciones de asistencia privada, etcétera, o bien, carecer de él por voluntad de sus miembros. ${ }^{5}$

Estas organizaciones se derivan de la iniciativa de los ciudadanos, así como de la acción de fuerzas religiosas, políticas y sociales, que buscan al ternativas para combatir la pobreza en sus múltiples formas. "Son producto dereacciones sociales frentea mecanismostradicionales" (A rmendares, 1994:1). Ahí dondeel Estado ha descuidado su atención, es especial, en la asistencia y desarrollo social, las ONG emergen como un coadyuvante derelativa importancia, eincluso, en ocasiones llegan hasta a sustituir completamente la función que debieran cubrir las instituciones gubernamentales.

Regularmente están formadas por técnicos y profesionistas comprometidos con asuntos sociales que los vinculan con los sectores populares, en torno a los cuales se definen programas y líneas deacción (Armendares, 1994:2).

Los destinatarios de sus esfuerzos suel en ser los sectores excluidos o desprotegidos de la sociedad, de quienes recogen sus demandas, reiteran la imperiosa necesidad de la participación ciudadana —en la formulación e instrumentación de políticas que den solución a problemáticas sociales-, y alientan al ciudadano a que sea partícipe en la resolución de sus propios problemas y los de la comunidad.

\footnotetext{
${ }^{5}$ Esta definición aunque es restringida, nos permite identificar las características esenciales deestos grupos, aquellos elementos quedistinguen a las ONG delos grupos ciudadanos que se organizan para obtener beneficios particulares.
} 
Su actividad se basa fundamental mente en el trabajo de ciudadanos voluntarios quienes, en ocasiones, reciben pequeños apoyos económicos. La clave de su éxito radica, precisamente, en el tiempo y la entrega de sus miembros a causas queantes sólo asumían los militantes departidos políticos, principalmente deoposición.

Algunas ONG plantean la necesidad de implantar un estado de derecho basado en la acción combinada entre Estado y sociedad, sin pretender suplantar el papel que debe tener el Estado. Otras abordan los problemas desde una perspectiva ética, destacando la importancia delajusticia social. Otros dedican sus acciones a actividades meramente asistencialistas. Otras más, tienen objetivos muy precisosqueaparentan contribuir con el desarrollo social; sin embargo, en ocasiones terminan por imponer criterios ajenos a las comunidades queatienden, tal es el caso del sector rural de los países latinoamericanos.

Entre los cuestionamientos más fuertes que se les hacen a las ONG está el deque, a pesar deimpulsar procesos horizontal es en la toma de decisiones, ellas mismas carecen deestructuras internas que posibiliten desarrollar tales procesos. En ese sentido, tienen límites importantes que impiden un mayor desarrollo de la educación ciudadana en la población queatienden.

Aunque en el mundo delas ONG la mayoría tienelos rasgos quese mencionan anteriormente, existen algunas que tienen objetivos contrarios a los intereses de los grupos marginados. Es decir, también sepresentan casos deorganizaciones ciudadanas queson el "camuflaje" departidospolíticosy un número considerabledeoN queresponden a intereses políticos de los países ricos.

Al respecto, también es importante mencionar que hay corrientes dentro del pensamiento de izquierda quecritican férreamenteel papel de las ONG. Un caso destacado es el del escritor James Petras, quien sostienequeestos organismos son colaboracionistas con los gobiernos, "porqueactúan en un marco deno enfrentamiento; sus ideologías desvían la atención de la causa de la pobreza, sólo llegan a una porción de la población y lo que es más importante, compiten con las organizaciones y movimientos sociopolíticos, dividen comunidades y socavan la solidaridad de clase" (Viñuelas y Wyatt, 1997:30). 
Con otros argumentos, aunque en el mismo sentido crítico, los sectores conservadores también arrecian sus cuestionamientos contra las ONG, al acusarlas deser "dilapiladoras derecursos eineficientes en el manejo de éstos, que terminan por convertirse rápidamente, en agencias decolocación deexfuncionariosgubernamentales" (Viñuelas y Wyatt, 1997:29).

En suma, desde la perspectiva de Viñuelas y Wyatt (1997:29), tal parece que las ONG son víctimas de una pinza de derecha eizquierda. Seles ubica a todas como idénticas, sin comprender la heterogeneidad que existey, en algunos casos, sehace deellas una ideal ización que, al verse frustrada, seconvierteen enojo. Su conclusión es quelas ONG no son ni heroínas ni villanas. No son la respuesta a los problemas, pero tampoco son el problema.

Laaparición deiniciativas deciudadanos organizados y la creación de ONG en el mundo no es algo novedoso. En la Europa del siglo XIX surgieron grupos al truistas y filantrópicos que bien podrían ubicarse dentro de esta categoría. ${ }^{6}$

Ya Tocqueville, en su obra La democracia en A mérica (1979), considerabala participación voluntaria delos ciudadanos en asociaciones privadas como un pilar dela cultura democrática delos estadounidenses del siglo xIX. Lo novedoso es la trasnacionalización dela participación cívica, nos dice Thorup (1995:155), mediantela construcción deredes y coaliciones deoN quetratan deinfluir en las decisiones depolítica pública y política exterior.

En nuestro país, aunquela aparición delas ONG data demás detres décadas, hay concordancia en la mayoría de los autores de que es a partir del sismo de 1985 en la ciudad de México, cuando comenzaron a tener presencia en la vida pública. ${ }^{7}$

\footnotetext{
${ }^{6}$ Una de las primeras ONG reconocida mundialmente es la Cruza Roja. Al decir de Thorup, la primera ONG reconocida como tal, "La Agencia Internacional por la Paz", se creó en 1892, en Suiza, (Thorup, 1995:166).

${ }^{7} A$ un y cuando ya existían al gunas organizaciones en los estados de la república, quetenían cierto prestigio.
} 
Durante los años cincuenta y sesenta, aparecieron organismos que pretendían llevar programas de desarrollo a la comunidad, principalmenteubicados en el campo mexicano.

Enseguida surgieron los centros de apoyo asistencial y los grupos de derechos humanos como el Frente Nacional Contra la Represión; posteriormente, el grupo Eureka, quese constituyó para luchar por los presos y perseguidos políticos del paísy, después, los Centros deA poyo al Movimiento Urbano Popular.

En losúltimos años, a las ONG seles menciona con mayor frecuencia en tres ámbitos de la vida nacional que, de acuerdo con Coulumb (1997:227) son: 1) en relación con los cambios sociopolíticos, específicamentecon el proceso de democratización dela vida políticoelectoral; 2) con la lucha por los derechos humanos; y 3) en relación con el proceso de pacificación del conflicto en Chiapas.

En la frontera norte, y en Baja California en particular, las ONG son un fenómeno social relativamentenuevo. Si bien existen al gunosgrupos queseconformaron desdehacemás deveinteaños, es hasta mediados de los ochenta cuando comenzaron a tener una presencia importante en la entidad. Las ONG que tienen mayor antigüedad, son aquéllas que se dedican al apoyo y defensa de los trabajadores migratorios, tal es como el Centro de Investigaciones y Estudios Migratorios (CIEM) y el Centro Binacional de Derechos Humanos (CBDH).

En la región fronteriza San Diego-Tijuana, zona de grandes interacciones transfronterizas, es donde, por naturaleza, han proliferado máslas ONG deapoyo a losmigrantes. Es precisamenteen laregión del norte de nuestro país y del sur de los Estados Unidos, donde la política económica mexicana y la política de control migratorio estadounidense tienen un encuentro estrepitoso, encarnado en la migración indocumentada que intenta internarse en territorio del país vecino en busca de mejores perspectivas laborales. Ese choque es devastador, así lo indican sus consecuencias: muertes, maltratos, racismo, xenofobia, dispersión familiar y anhelos diluidos; en suma, violación a los derechoshumanos. Deahí quela sociedad civil fronteriza se preocupe y organice grupos para la cooperación y defensa de los trabajadores migratorios. 
Duchacek (1986) menciona quela proyección de necesidades eintereses subnacionales o locales sobre la escena internacional, ha asumido dos formas distintas: la microdiplomacia (o paradiplomacia) y el regional ismo transfronterizo. Mientras quela microdiplomacia refleja la conciencia subnacional de la interdependencia global, en la cual los actores locales buscan insertarse, el regionalismo transfronterizo representa una respuesta decooperación (circunscrita geográficamente) a riesgos y oportunidades que se originan por la vecindad territorial. En ambos casos, los actores locales han dirigido sus miradas hacia el exterior, más allá de las fronteras.

Si bien es cierto que con la intención de promover intereses locales y mejorar la situación de la región que representan, han sido actores gubernamentales subnacionales los que mayor impulso han dado a este tipo deacciones paradiplomáticas, también es cierto que, a partir de esta década, han empezado a destacar otro tipo de actores que han dado un nuevo giro a las relaciones diplomáticas en la esfera internacional sobrediversos tópicos. Entreellos, las organizaciones no gubernamentales tienen un lugar sobresaliente. La participación dela sociedad civil en la arena de la política exterior, se enmarca más claramenteen lo que seha venidollamando la “diplomacia ciudadana”. Este concepto, creado por las propias organizaciones no gubernamentales, denota las acciones que desarrollan los ciudadanos organizados en ONG de un país para involucrarse en los asuntos de otro. Implica la usurpación de papeles considerados del dominio exclusivo de los actores gubernamentales; es decir, de la diplomacia gubernamental (Thorup: 1995; 156).

A decir deCathryn L. Thorup (1995; 157),

los ciudadanos particulares [...] están desempeñando un papel de creciente importancia en el establecimiento de los parámetros de la agenda de política exterior, al limitar la capacidad de los funcionarios públicos para manejar sus relaciones en una base estrictamente de gobierno a gobierno, 
y montar el escenario para un proceso de interacción mucho más complejo. ${ }^{8}$

Según Heredia y Hernández (1996), no todas las actividades ciudadanas de carácter internacional deben ser consideradas como diplomacia ciudadana. "Para serlo deben definirse en función de la presencia einfluencia políticas quelos ciudadanosy las ONG traten de hacer ante los centros de poder mundial". Para estos autores, los componentes centrales de una diplomacia ciudadana estarían encuadrados en las actividades de cabildeo a gobiernos extranjeros y organismos multilaterales; también la construcción de redes internacionales no gubernamentales: temáticas y profesionales; así como el desarrollo de proyectos de investigación y construcción de políticas alternativas diferentes a las trazadas por los gobiernos y organismos financieros internacionales; y de manera primordial, el establecimiento de canales de información y comunicación regulares, a través de conferencias mundiales por correo el ectrónico, cumbres de discusión en la ONU, etcétera.

Esto es más claro en los países del primer mundo, donde las organizaciones civiles pueden desarrollar mayor influencia en la definición de la política exterior de los países o de ciertos sectores económicos. Ejemplo deello lo tenemos en la presión ejercida, durante varias décadas, por Amnistía Internacional y otras organizaciones defensoras de los derechos humanos contra la política del A partheid en Sudáfrica, hasta lograr quevarios países seabstuvieran demantener relaciones diplomáticas con el gobierno deesa nación. También la acción de esta misma ONG internacional, Ilevó a que las Naciones Unidas

${ }^{8}$ Tal vez el caso más ilustrativo para nuestro país de lo que venimos comentando, sea la reunión del presidente Zedillo en Francia, en octubre de 1997, con organizaciones de derechos humanos europeas, en donde se observó la importancia que tiene la opinión de estos grupos para la definición de una política de relaciones exteriores adecuada. 
aprobaran, primero la resolución y luego la convención contra la tortura (Ghils, 1992:447).

Otros ejemplos sepresentan con el papel quejugaron las organizaciones ambientalistas y laborales estadounidenses y canadienses durantela discusión sobreel Tratado de LibreComercio entreM éxico, Estados Unidos y Canadá. En este caso, la presión ejercida logró que la agenda de discusión inicial entre los gobiernos participantes se modificara, para quefinalmenteseconsiderara paral elamenteel efecto ambiental del TLCAN $^{9}$ y la necesidad de volver a capacitar a los trabajadores y otros mecanismos de ajuste. Todo esto con el objetivo de poner algunos candados a las pretensiones de los empresarios estadounidenses de instalar plantas industriales en el lado mexicano, sin tomar en cuenta medidas estrictas en cuanto a riesgos de contaminación ambiental.

En ese mismo tenor se encuentran las luchas que desarrollan la organización Green Peacey PesticideAction Network, contra la entrada dedesechostóxicosy pesticidasalospaíses de tercer mundo; y, finalmente, el papel delosgruposambiental istasprotectoresdel delfín, queinfluyeron en el embargo del atún mexicano. ${ }^{10}$

Ghils (1992) menciona tres formas en que las organizaciones internacionales no gubernamentales (oING como las denomina él) intervienen en los asuntos delos Estados. La primera, es en la adopción denuevas normas internacionales (en estecaso, las OING seconvierten

\footnotetext{
${ }^{9}$ Durante las discusiones del TLCAN, las ONG canadienses lograron "filtrar" al congreso mexicano y a los medios de comunicación, una versión del documento que estaban por aprobar los gobiernos estadounidense y mexicano, lo que provocó una gran polémica en los círculos políticos de oposición. En esta acción mucho tuvieron quever los nexos quemantenían las ONG deCanadá y la red mexicana contra el Tratado de Libre Comercio.

${ }^{10}$ Lo anterior no excluye quelas ONG no sean sujetas de manipulación por partede ciertos intereses económicos, lo cual fue evidente con el caso del atún mexicano; al respecto, consúltese a Raúl Páez Delgado, M ercado global del atún y embargo estadounidense (un caso de neoproteccionismo comercial),(1997).
} 
en grupos de presión). Un segundo tipo de intervención es la acción directa de éstas en el plano transnacional, ya sea a favor de sus miembroso degrupos sociales particulares, especialmentelos queestán en una situación vulnerable (migrantes, refugiados, etcétera). Una tercera categoría de intervenciones se presenta en ámbitos en que los gobiernosno intervienen o son impotentes, y entonces las ON G desafían abiertamenteel orden estatal o interestatal - a veces en forma de movimientos sociales poco estructurados, o en formas encaminadas a modificar las estructuras estatales.

Las formas de intervención que adquieren mayor relevancia, son aquéllas en las cuales las ONG nacionales se enlazan con otras de diferentes países para intentar influir en las agendas de las Ilamadas cumbres y conferencias de discusión internacional realizadas por la Organización delas Naciones Unidas. En estecaso, los grupos debase presentan sus informes sobre la situación preval eciente en sus países. En al gunas ocasiones logran introducir sus planteamientos mediante la participación directa, conjuntamente con las representaciones gubernamentales; en otras, se ven obligadas a realizar "cumbres paralelas" a las oficiales. ${ }^{11}$

Las acciones de "presión" - directas o indirectas- de las ONG, no secircunscriben a un solo patrón, pueden ir desdela simple denuncia en los medios (acompañadas por firmas de apoyo), el Ilamado lobby ${ }^{12}$

${ }^{11}$ Delas cumbres internacionales quehan tenido una participación relevantedelas ONG, o bien, delas quese han presentado "cumbres paralelas", setienen la Cumbre de Río sobre el medio ambiente, efectuada en 1992, las conferencias organizadas por la ONU , en 1993 y 1995, sobre los derechos humanos, dela mujer y desarrollo social, así como la cumbre en favor de la infancia.

12 Este concepto, nos indica Bobbio (1981), es el proceso por medio del cual los representantes de grupos de interés o de presión, actuando como intermediarios, ponen en conocimiento de los legisladores los deseos de sus grupos. Por lo tanto lobby o lobbying es, sobretodo, una transmisión demensajes delos grupos deinterés o presión. En Estados Unidos, por ejemplo, para llevar a cabo el trabajo de lobby resulta necesario contratar los servicios de agentes profesionales, los cuales están legalmente autorizados para ejercer esas actividades. 
durante los foros de discusión internacionales, o el "cabildeo" ${ }^{13}$ que real izan las organizaciones con los representantes populares antelos congresos nacionales, hasta las acciones más radical es de bl oqueos y huel gas dehambre. A demás, la participación en el exterior tieneuna directa relación con el papel que juegan las ONG en problemáticas domésticas, en donde sus intervenciones están tomando una importancia crecientey cada vez tienen también mayor influencia en aspectos depolítica pública.

Hay algunas actividades, como la búsqueda de fondos o donaciones de agencias internacionales para la cooperación, que no forman parte de la diplomacia ciudadana, salvo aquéllas que se presentan como una presión política directa sobrelos gobiernos delos donantes o entidades de cooperación. Los intercambios académicos y programas conjuntos entre universidades tampoco son, por sí solos, diplomacia ciudadana, sólo aquéllos queestán dirigidos a una acción política, aunque sea en forma indirecta (Herediay Hernández; 1996:6).

Aunque la diplomacia ciudadana, en el sentido sugerido en este trabajo, serefieremásal activismo para influir en las agendas depolítica exterior, el concepto no excluye la participación de organismos ciudadanos o de base que intentan influir en las políticas públicas domésticas, o que pretenden impulsar una cultura ciudadana de participación activa, quelleve a la concientización dela sociedad y al

\footnotetext{
${ }^{13}$ Cabildeo, aunque frecuentementees utilizado como sinónimo delobby, realmente, nos dice el D iccionario de la lengua española (1983), se refiere a la gestión pero acompañada de acciones de presión más directa como la amenaza, de tal forma quelos grupos pretenden ganar voluntades delos legisladores utilizando "mañas". Por su parte, la organización no gubernamental Equipo Pueblo, que utiliza como sinónimo cabildeo y lobby, nos dice que: “Desde las organizaciones no gubernamentales se entiende cabildeo la acción de abordar a los agentes gubernamentales para incidir tanto en su percepción de los asuntos públicos como en las decisiones que adoptan al respecto, mediante la canalización de información contextual desdela perspectiva de grupos ciudadanos, movimientos populares y organismos no gubernamentales; $y$ a través del planteamiento de propuestas para ser adoptadas por el poder ejecutivo o el legislativo como políticas públicas" (Herediay Hernández, 1996).
} 
mismo tiempo a crear la base para establecer "poderes" ciudadanos quecompitan con los gubernamental es. Al respecto, resultailustrativo la misión que plantea desarrollar la organización no gubernamental mexicana Equipo Pueblo, en cuyos documentos define "el impulso de programas alternativos de desarroll o social, la elaboración depolíticas públicas y la diplomacia ciudadana, para contribuir a la construcción deun poder civil y una cultura ciudadana capaces de proponer, administrar y vigilar los asuntos dela vida pública de México y aportar una propuesta de proyecto nacional, para el logro de la justicia social y la democracia." (Coulumb, 1997:230).

De igual manera, en las diferentes redes nacionales de ONG, se observa una clara definición hacia un compromiso por el cambio social y una reestructuración de las relaciones Estado-sociedad, lo que ha llevado a las organizaciones civiles a proponer una redefinición de lo público y lo privado.

La red nacional deorganizaciones no gubernamentales denominada Foro de A poyo Mutuo (FAM), en uno de sus objetivos expresa nítidamentelo que se comenta: "construir a partir de la práctica directa y como una expresión importante dela sociedad civil, propuestas depolíticas públicas quepuedan contribuir a formular las políticas del Estado en materia de desarrollo social" (Coulumb, 1997:231).

Algunas de las acciones de las ONG que pudieran considerarse de magnitudes importantes en nuestro país, aunque no necesariamente influyentes, han sido la lucha del Grupo de los Cien contra la planta nucleoeléctrica Laguna Verde; el movimiento en defensa delos presos, desaparecidos y perseguidos políticos dirigido por Rosario Ibarra; las luchas de las organizaciones de colonos en el Distrito Federal por el suelo urbano y los damnificados del sismo de 1985; la presión para modificar las leyes el ectorales federales y estatales de la red de ciudadanos A lianza Cívica, y recientemente, la presión ejercida por las organizaciones no gubernamentales de derechos humanos hacia las autoridades del gobierno federal para mantener la paz en Chiapas y castigar a los culpables de los asesinatos pol íticos ocurridos en esa entidad.

Cabría preguntarnos: ¿qué representatividad social guardan esas organizacionesque pretenden servir decontrapeso al poder del Estado 
en regiones y campos normativos, y quebuscan influir en el cambio de políticas públicas y agendas internacionales?

Si bien es cierto, las ONG carecen de una representación efectiva por mandato o del egación que las limitaría en sus al cances, su acceso a la voz pública produce un efecto de representatividad, ya queasumen, por lo general, objetivos socialmente legítimos. Y esa representación simbólicasemagnifica cuando las organizaciones ciudadanas seocupan deasuntos queson deinterés mundial, como la defensa delos derechos humanos. Además, la existencia de un sistema eficiente de comunicaciones y de múltiples canales agiliza y da mayor potencia al efecto magnificador; es decir, al margen efectivo deacción que pueden tener amplios sectores de la población (Gordon, 1997:63).

La experiencia de trabajo que han acumulado algunos de estos organismos, les ha permitido establecer contactos con grupos deotros países y figurar en el ámbito internacional. Tal es el caso de las redes deorganizacionesno gubernamentalesTodos losDerechosparaTodos, quemantienerelaciones estrechas con Amnistía Internacional; el Frente por el Derecho a la Alimentación, queestá relacionado con redes internacionales sobreesamisma temática; la Red MexicanadeAcción Frente al Tratado deLibreComercio; la Convergencia de Organismos Civiles por la Democracia, quemantienerelaciones estrechas con la fundación Terre des Hommes-Icaria Antrazyt (Tierra de Hombres) de Francia, etcétera. Con sus acciones, todos estos grupos han estado desarrollando formas de diplomacia ciudadana, tanto a escala nacional como transfronteriza. ${ }^{14}$

En Baja California, los organismos que han destacado son los que trabajan en el campo de los derechos humanos de las mujeres y los trabajadores migratorios. Las ONG de este tipo han ganado mayor

${ }^{14}$ En el caso deConvergencia de Organismos Civiles por la Democracia y Terredes hommes-Iccaria Antrazyt, entre los acuerdos que tienen, están aquéllos que van 
presencia en los últimos años por su activismo constante. Entre estas organizaciones seencuentran la Coalición deM ujeres deBaja California y la Coalición Pro Defensa del Migrante.

Igual mente, en Estados Unidos, han proliferado grupos queluchan por los derechos civiles de los latinos en ese país, para exigir un mejor trato haciala comunidad hispana por partede autoridades migratorias y de otras autoridades legales estadounidenses. Estos organismos fueron apareciendo en diversas ciudades del sur, ubicadas en la frontera con M éxico. En San Diego, Cal ifornia, al gunas delas organizaciones que tienen mayor antigüedad son American Friends Service Committee; OneStop Immigration and Educational Center, Comisión Binacional deOrganizaciones H ispanas en California; Asesoría Legal Rural deEstados Unidos, y la Asociación deA bogados delaFrontera.

Al igual que sus contrapartes mexicanas, al gunas de estas organizaciones también han logrado establecer redes a lo largo delafrontera con México, tal es el caso del A merican Friends ServiceCommiteeque tiene ramificaciones en los estados de Nuevo M éxico y Texas.

\section{REDESY COALICIONESTRANSFRONTERIZAS: ANTECEDENTES ${ }^{15}$}

El acercamiento entreoNG de ambos lados dela frontera queabordan la temática de derechos humanos y la asistencia a los migrantes, tiene como antecedentes la Coalición para Políticas Migratorias Justas y la Red Nacional para los Derechos de los Inmigrantes y Refugiados,

encaminados a fortalecer la articulación de las diferentes organizaciones de base en algunas regiones de M éxico, y desarrollar procesos de investigación sobre los compromisos adoptados por nuestro país anteel Pacto Internacional deDerechos Económicos, Sociales y Culturales (PIDESC), en los informes que presenta al Consejo Económico y Social(Ecosoc) de la Organización de las N aciones Unidas.

${ }^{15} \mathrm{H}$ ay que hacer notar que contra lo que pudiera pensarse, los conceptos de red y coalición tienen sus especificidades quelas distinguen. La red se refiere más a una agrupación temporal de organizaciones, que constituyen un foro de discusión e 
formadas en Estados Unidos durante la discusión de la, entonces iniciativa deley, Simpson-Mazzoli, entre1982 y 1983y, posteriormente la Ley Simpson-Rodino, de 1986. Aunque esos acercamientos fueron coyunturales e informales, permitieron que las ONG estadounidenses comenzaran a tener contacto con sus contrapartes mexicanas.

A finales de los años ochenta y principios de los noventa, se establecieron algunos esfuerzos de cooperación conjunta entre organizaciones no gubernamentales de ambos países. Estos vínculos fueron impulsados por organizaciones quetienen años trabajando por los derechos de los migrantes en Tijuana y Mexicali, y el área de San Diego. Los enlaces fueron hechos, en esos tiempos, por el Centro de Investigación y Estudios Migratorios (CIEM), el Comité Binacional de Derechos Humanos, el Albergue Juvenil del Desierto, y el Centro de A poyo al Trabajador Migrante ${ }^{16}$.

intercambio de información y socialización de prácticas y metodologías de trabajo. La coalición se refiere a una forma de organización más formal, donde los agrupamientos adquieren mayores compromisos con la entidad quelos representa. A unqueambas constituyen entidades informales, las fronteras entre una y otra, en realidad no están bien definidas; en ocasiones de una red surge una coalición y viceversa. En nuestro país existen al gunas redes importantes de ong como Convergencia de Organismos Civiles por la Democracia y el Foro de A poyo Mutuo; de igual manera, existen coaliciones como Alianza Cívica y la Coalición Pro A poyo al Trabajador Migrante.

Cuando hablamos de coal iciones transfronterizas, nos referimos a las agrupaciones civiles que se comprometen, cuando menos temporalmente, a desarrollar actividades conjuntas, sean éstas decarácter formal o informal, a través delas fronteras nacionales. (Thorup, 1995:158), lo cual significa que no necesariamente son transfronterizas por la contigüidad geográfica. Ejemplo de ello lo tenemos con las coaliciones que se formaron para hacerle frente al Tratado Trilateral de Libre Comercio en Canadá, Estados Unidos y México.

${ }^{16}$ La Procuraduría de Derechos Humanosy Protección Ciudadana deBaja California, aunque es un organismo gubernamental, ha trabajado muy cerca con las organizaciones de derechos humanos y de apoyo a los migrantes de ambos lados dela frontera e, incluso, en varias ocasiones ha hecho el papel decoordinación delas redes y coaliciones que se han conformado. 
Paradójicamente, los primeros acercamientos demanera másformal entrelas ONG deambos países, los propició el propio gobierno mexicano, al establecer algunas reuniones en el Consulado M exicano en San Diego. Deesos encuentros surgió la Coal ición Hispana para la Defensa de los Derechos Humanos del Condado de San Diego (Thorup, 1995:189). La intención delas autoridades mexicanas en Estados Unidos era expandir los servicios consulares, con el propósito deestrechar los lazos entre el gobierno mexicano y la comunidad latina radicada en Estad os Unidos, razón por la cual se le dio una apertura inusitada a los cónsules mexicanos, para quefueran ellos los que cumplieran con tal cometido.

De los intentos que se han realizado para establecer lazos transfronterizos entre organismos no gubernamentales de carácter nacional, destacan los encabezados por la A cademia M exicana deDerechos Humanos en 1991, con la organización de Conferencias Trinacionales sobre Derechos Políticos y Humanos (Thorup, 1995:196); así como el evento promovido por esta misma organización no gubernamental mexicana y la Universidad de Georgetown y York, en la Conferencia Trinacional sobre Migración, efectuada en el año de 1992 en territorio estadounidense, donde participaron diversas organizaciones defensoras delos derechos humanos de los migrantes mexicanos y centroamericanos.

De singular importancia resultan las redes informales que se han integrado para participar en los eventos quelosgobiernos delos países del tratado trilateral de libre comercio han realizado en los últimos años en Puebla (M éxico), Panamá, Canadá y Guatemala. A esos eventos se les ha denominado Conferencias Regionales sobre Migración, y tienen la finalidad de discutir políticas en materia de migración.

Efectivamente, durante el desarrollo de esos encuentros, las redes de ONG defensoras de los derechos humanos de los migrantes, han intentado participar en forma directa en las discusiones sobre la problemática delosmigrantesindocumentados. En el primer encuentro, quese desarrolló en nuestro país, las ONG sólo tuvieron la oportunidad de introducir sus propuestas por escrito, ya que los representantes gubernamentales no aceptaron su participación. 
En el segundo evento, efectuado en Panamá, fue posible que las organizaciones no gubernamentales hicieran presencia, pero a nivel de lobby, para introducir sus propuestas. Sin embargo, en la reunión de 1998, efectuada en Canadá, las ONG por fin, pudieron lograr un espacio, una silla en la mesa de discusiones junto a los representantes gubernamentales, lo cual constituyó un avance importante para estas organizaciones. ${ }^{17}$

En esos foros, I a diplomacia ciudadana transfronteriza se ha hecho presente. Es decir, como resultado deestas experiencias, se ha logrado conformar una red de carácter regional que incluye organismos de México, Estados Unidos y Centroamérica, la cual ha sido nombrada Red Informal sobreMigración.

Las experiencias consideradas más impactantes de coaliciones y redes fronterizas surgieron cuando se dio a conocer el operativo de vigilancia-establecido por el gobierno federal delosEstadosUnidos_denominado Operación Guardián, que entró en vigor el 1 de octubre de 1994, y que en 1997 inauguró su tercera fase, así como de la propuesta Save Our State(sos), mejor conocida como la Proposición 187, que se planteó en septiembre de $1994 .{ }^{18}$

El tipo de redes y coaliciones que generaron esas acciones sobre política migratoria, presentaron características muy disímbolas, con miembros de la sociedad civil de diferentes clases sociales, razas y credos, de las cuales se trataran en apartados posteriores.

\footnotetext{
${ }^{17}$ Cabemencionar quela mayor oposición a la participación delas ONG 'sen la mesa donde estarían los representantes gubernamentales, provino del gobierno mexicano. Entrevista a Blanca Villaseñor Roca, representante de la Coalición Pro Defensa del Migrante, participanteen la reunión de Canadá. En eseevento, las organizaciones no gubernamentales presentaron un documento denominado IV Resolución de organismos no gubernamentales sobreel tema del fenómeno migratorio 1997, firmado por más de 100 organizaciones de M éxico, El Salvador, H onduras, Nicaragua, Panamá, Costa Rica, Belice, Canadá y Estados Unidos.

${ }^{18}$ La llamada Ley 187, entró en vigor en abril de 1997, pero posteriormentefue bloqueada en su gran mayoría, por un amparo queinterpusieron al gunas organizaciones civiles de Estados Unidos. Sin embargo algunas medidas lograron Ilevarse a cabo.
} 
Las experienciasy relaciones deredestransfronterizas sehan venido consolidando en los últimos años; un ejemplo de lo anterior, han sido los encuentros convocados por laUniversidad deChicago, desde1995 hasta 1997, medianteel programa deestudios mexicanos para discutir las políticas migratorias dela frontera M éxico-Estados Unidos. Dichos eventos han logrado conjuntar a un importante número de representantes de ONG de México, como la Red Sin Fronteras, la Coalición Pro Defensa del Migrante, laA cademia Mexicana deDerechos Humanos. De igual manera, han acudido organizaciones no gubernamentales de Estados Unidos, relacionadas con los derechos humanosy el fenómeno migratorio.

Como resultado de estos encuentros, ha surgido una red informal transfronteriza denominada A $n$ Iniciative of the H eartlan Alliance for Human Needs and Human Rights (Boletín N etwork M exico-USA, A dvocates, 1997), que no sólo se dedica al análisis de la problemática migratoria, sino que, paulatinamente, seestáconvirtiendo en un espacio dedenuncia y presión a las políticas estadounidenses sobrela materia. Esos eventos también se constituyen en espacios privilegiados para dar seguimiento a los encuentros que han desarrollado los gobiernos deEUA, Canadá y México, para discutir el problema migratorio.

En el caso específico de las experiencias de las organizaciones de apoyo a migrantes deBaja California, la mayor partedeellasselocaliza en la región Tijuana-San Diego, por ser ésta la zona más directamente afectada por el flujo migratorio hacia Estados Unidos. Sin embargo, a raíz de las políticas estadounidenses, organizaciones con fines similares en M exicali y Tecate, están tomando un papel más protagónico y, de ser meramente de asistencia, están asumiendo ahora un rol de interlocutoras de quienes no tienen voz. Estas ONG han empezado a real izar acciones conjuntas con grupos que trabajan en el campo de la migración en California -específicamente en el condado de San Diego- a través de la conformación de redes y coaliciones (Thorup, 1995: 185). ${ }^{19}$

También oNG de Mexicali y San Diego mantienen vínculos constantes para intercambiar información sobre la documentación de casos de violación de derechos humanos por parte de la patrulla 
fronteriza de los Estados Unidos. A unqueestas coordinaciones se iniciaron en 1994, han presentado mayor consolidación a partir de 1996, debido a la intensificación de las medidas antiinmigrantes de la Operación Guardián.

Con el conocimiento mutuo en el trabajo de base por parte de las organizaciones, poco a poco se han venido estableciendo canales de comunicación que estrechan los vínculos de cooperación transfronteriza.

Todo esto está permitiendo a los organismos no gubernamentales fronterizos, contar con mayores argumentos para fundamentar quela violación a los derechos humanos es cada vez más grave, y que es necesariala intervención delos gobiernos deEstados Unidosy M éxico, para tratar el asunto migratorio desde una perspectiva binacional .

\section{MEDIDASANTIINMIGRANTESY RESPUESTASCIUDADANAS TRANSFRONTERIZASEN LA FRONTERA BAJA CALIFORNIA-CALIFORNIA}

La constatación empírica delos procesos de diplomacia ciudadana que se vienen presentando en la zona fronteriza de Baja Cal ifornia, se da principalmente en el ámbito de la defensa de los derechos humanos de los trabajadores migratorios. Y, precisamente, son más evidentes cuando observamos las respuestas quese presentaron, en ambos lados dela frontera, antelas medidas antiinmigrantes desarrolladas por los gobiernos federal y estatal de Estados Unidos desde 1994.

A decir dealgunos estudiosos, la región Baja California-California - particularmente la frontera Tijuana-San Diego California_ es de

\footnotetext{
${ }^{19} \mathrm{El}$ acercamiento con grupos de San Diego se debe, fundamentalmente, a que no existen organizaciones defensoras de los migrantes en Cal éxico y Tecatito (contrapartes fronterizas de M exicali y Tecate), excepto una oficina de One Stop, que trabaja eventualmente en Caléxico, y la representación del Sindicato de Trabajadores Agrícolas de California (fundado por César Chávez).
} 
las más prósperas y con un gran dinamismo económico y demográfico, en comparación con el resto de las zonas fronterizas mexicanas con Estados Unidos (Clement, 1996). Esta región es testigo de una gran cantidad de interacciones transfronterizas, comerciales, sociales y culturales que la hacen estar cada vez más integrada.

Si bien es cierto que ambos estados fronterizos (Baja California y California) establecen lazos cada vez más estrechos, también lo es el hecho que cada uno pertenece a dos países muy distintos, con desarrollos económicos asimétricos, y con percepciones muy diferentes sobre problemáticas comunes, que se tornan más críticas en la región. Sin duda, el flujo migratorio de mexicanos hacia Estados Unidos constituyeuna deesas problemáticas que dan cuenta dela desigual dad de ambas naciones, y que en la zona fronteriza se hace presente.

La migración de trabajadores mexicanos indocumentados hacia Estados Unidos es un problema controversial y añejo en la relación bilateral México-Estados Unidos. El flujo migratorio ha sido tratado por uno y otro país con diferentes visiones. En el caso mexicano, se perci becomo un problema económico y devecindad entredosnaciones con diferentes desarrollos económicos. En cambio, la percepción de los Estados Unidos ha sido verlo como un problema detipo policiaco e incluso ideológico-político, argumentado en la "ilegalidad" de las personas que realizan el cruce.

Debido a ello, en la región Baja Cal ifornia-California se presentan acciones que pudieran ser consideradas de militarización para establecer un máximo control sobre la frontera ${ }^{20}$ y el inicio de una "campaña de deportaciones de trabajadores y familias sin documentos desde el interior de los Estados Unidos" (Pérez, 1997). La frontera

\footnotetext{
${ }^{20}$ Algunos autores mencionan que ese proceso de militarización responde a una estrategia más sofisticada a la cual denominan "la guerra de baja intensidad"; al respecto véase Raúl Ramírez, “La migración en la globalización”(1998).
} 
nortemexicana es testigo dela crecienteviolación de derechos humanos de que son objeto los migrantes indocumentados al ser detenidos y deportad os por las autoridades migratorias estadounidenses.

Las recientes políticas de endurecimiento hacia la migración indocumentada han traído como consecuencia el incremento de expulsiones (deportaciones), en forma masiva, de trabajadores mexicanos quelaboran en los EstadosUnidossin documentos, situación que ha tomado tintes más dramáticos a raíz de la puesta en marcha de la Operación Guardián y la Proposición 187.

A mbas políticas antiinmigratorias generaron reacciones de rechazo en los dos lados de la frontera, ${ }^{21}$ - tanto por amplios sectores de la sociedad mexicana como por parte dela población latina que viveen Estados Unidos- por ser consideradas como violatorias delos derechos humanos y por tener tintes racistas en contra de los migrantes indocumentados, particularmentedeorigen mexicano; aunquedel lado estadounidense tuvo mayor impacto la Proposición 187, porqueafectó directamentea la población de origen latino.

Ante esta situación, las autoridades de México asumieron una actitud que, ajuicio delas ONG, no respondió de una manera enérgica como se esperaría, debido, entre otras cosas, a queel tema migratorio no ha querido tratarse desde una perspectiva laboral porque, como señala Bárbara Driscoll, "un sector importante de la sociedad y del gobierno mexicanos han considerado que el movimiento de los trabajadores al norte ha funcionado como una especie de válvula de escapeparaal iviar muchas presiones" (Driscoll, 1996:15), como la falta de empleo, y porque son una fuente importante de divisas. ${ }^{22}$

${ }^{21}$ No significa queestetipo demedidas sólo generó manifestaciones derechazo de la población, también hubo expresiones a favor. Esto es claro en la victoria que obtuvo en las votaciones la Proposición 187. Sin embargo, aquí sólo estamos analizando las reacciones que defendieron los derechos humanos de los migrantes.

${ }_{22} \mathrm{Al}$ respecto, se considera que los Ilamados "migradólares" se han convertido en la tercera fuente de divisas del país, por abajo del petróleo y las maquiladoras. 
Sin embargo, otros sectores como al gunos sindicatos y organizaciones no gubernamentales de derechos humanos dela sociedad mexicana, están conscientes de que el tema migratorio merece ser anal izado desde otra perspectiva, en la que se tome en cuenta "las condiciones inaceptables de trabajo y de vivienda; los suel dos bajos y las violaciones delos derechos humanos básicos" (Driscoll, 1996:15). En estecontexto, las ONG de ambos lados de la frontera que están orientadas a otorgar asistencia a los migrantes y a defender sus derechos, incrementaron sus acciones de defensa y reforzaron vínculos transfronterizos.

Deesta forma, real izaron algunas actividades conjuntas deimpacto local (combinadas con algunos intentos para incidir en el ámbito nacional eincluso en la escena internacional), a fin dellamar la atención delos gobiernos centrales involucrados (M éxico y Estados Unidos), para que se abordara el asunto migratorio con enfoques más humanitarios.

Desde esta perspectiva, las organizaciones no gubernamentales de apoyo a los migrantes, local izadas en el condado deSan Diego y en las ciudades fronterizas de Tijuana y Mexicali, desplegaron una serie de actividades, que pretendían influir en algunas decisiones de política públicay relaciones entrelos dos países, detal forma quebeneficiaran la situación delos migrantes.

Aunque hubo quienes manifestaron queestas políticas migratorias, en su inicio no generaron ningún fenómeno de alarma respecto a la acumulación demigrantes (Bustamante, 1994) en las ciudades deBaja Cal ifornia, las organizaciones defensoras de derechos humanos en esta frontera denunciaron que el problema se estaba agudizando y que la capacidad de sus apoyos en cuanto a alimentación y albergue, resultaban insuficientes para atender a la población queestaba siendo deportada, por lo que se hacía necesario establecer un plan de emergencia para recibirla. A nteesto, los organismos quetrabajan con migrantes, tanto en el área de San Diego como en las ciudades fronterizas deTijuana y Mexicali, dieron inicio a una seriedeacciones para enfrentar esta situación. Del lado mexicano fuepara dar atención y asistencia, mientras que del lado estadounidense para defender los 
derechos que eran violados, así como prestar asesoría y orientación a sus contrapartes mexicanas. ${ }^{23}$

Los acercamientos devinieron en algunas redes incipientes deoNG, tanto a escala local como transfronterizo. A ntetal perspectiva, Thorup señala que

es en este contexto donde la diplomacia ciudadana y las coaliciones transfronterizas adquieren una gran importancia: proveyendo servicios a la población inmigrante, moldeando las políticas públicas en los ámbitos local, estatal y federal; desempeñando un papel fundamental al evitar y desarticular el conflicto, y ayudando a diseñar respuestas de la comunidad local ante la inmigración de mexicanos (Thorup, 1995:181).

En el área de San Diego y Los Ángeles surgieron organizaciones ${ }^{24}$ como H ispanos en Cal ifornia y A grupaciones M éxico-Americanas en Contra dela Proposición 187, que unieron a varias organizaciones de ambos condados; Coalición Intercredo en Defensa de los Inmigrantes, que enlazó a 60 organizaciones religiosas de California; la Unión Latinoamericana deA poyo al Inmigrante, compuesta por ciudadanos y organismos de Long Beach, California; Ia Alianza de Líderes Judíos y Afroamericanos contra la 187, queaglutinó a personas deesas razas

${ }^{23}$ A unque guardando toda proporción, el caso de las ONG de damificados del sismo de 1985, resulta ilustrativo delas tácticas delos grupos organizados; en este caso, ejercieron presión y lograron queal rededor decincuenta y cinco millónes de dólares fueran canalizados por organizaciones filantrópicas nacionales e internacionales antes dela ayuda gubernamental, lo cual potenció la capacidad de organización y presión de estos grupos. Al respecto, véase Emilio Duhau, “ Las organizaciones no gubernamentales y su participación en la reconstrucción", en P. Connolly et al., Cambiar de casa pero no de barrio. Estudios sobre la construcción en la ciudad de M éxico, CENVI/ UAM-Azcapotzalco, México, 1991.

${ }^{24}$ La información aquí contenida fue obtenida de notas periodísticas de los diarios El mexicano y Cambio deTijuana y La opinión de Los Ángeles, publicados entreel 1ro. y 30 de octubre de 1994. 
para erradicar la discriminación y el racismo en todas sus formas; Californianos Unidos Contra la Propuesta 187; Comité Organizador para Derrotar a la Proposición 187 y la Red de Representaciones Diplomáticas Mexicanas, que se estableció para auxiliar y orientar a los connacionales que solicitaran asesoría. Todas estas coaliciones se unieron al Ilamado que hicieron organizaciones latinas de defensa de los migrantes.

El máximo logro de todas estas organizaciones fue agruparse en la Coordinadora Nacional de Autodefensa y Participación Ciudadana, que aglutinó a más de 120 organizaciones de varios partes de Estados Unidos, pero principalmente deCal ifornia, para protestar en contra de la iniciativa sos del gobernador de California, Pete Wilson. Esta coordinadora vio cristalizados sus esfuerzos de difusión y concientización en contra de la 187, en una gran manifestación que se realizó en Los Ángeles, en donde, de acuerdo con los datos más conservadores, sereunieron 150000 personas (El mexicano, 17 deoctubre de1994), en señal deprotesta. Esta marchafueconsideradapor algunos medios de comunicación, como “la manifestación más importante en los Estados Unidos desde el movimiento afroamericano de 1963" (Cambio, 17 de octubre de 1994).

Los sentimientos de rechazo que generaron las medidas antiinmigrantes expresadas en la Proposición 187, conjugadas con el cierre militarizado dela frontera San Diego-Tijuana, dieron lugar a queotros sectores de la población se mostraran preocupados y se decidieran a realizar acercamientos y acciones conjuntas con sectores similares en su contrapartefronteriza. Por ejemplo, se llevó a cabo una reunión de obispos deCalifornia y Baja Cal ifornia, para discutir la postura antela 187; seefectuó una reunión en la que participaron diputados federales deBaja California, Chi huahua, Sonora, y Tamaulipas, y representantes diplomáticos de Estados Unidos para analizar la situación de xenofobia y racismo en contra de los mexicanos (EI mexicano, 3 de octubre de 1994:13-A). Asimismo, se establecieron contactos para realizar un monitoreo de deportaciones y presentar un informe en coordinación con grupos de derechos humanos deSan Diego y M exicali, para conocer cómo se estaban llevando a cabo las expulsiones. 
En estemismo sentido, en octubrede 1994, organizaciones del Valle Imperial y Mexicali realizaron marchas simultáneas. A mbas culminaron en la línea divisoria M exicali-Caléxico. La visión quedieron los medios de comunicación sobre el evento fue la siguiente:

a través del cerco fronterizo que divide los dos países se unieron [...] Por más de 45 minutos, las fronteras desaparecieron y los residentes de las dos ciudades unieron sus espíritus, sus voces y sus protestas, contra la proposición 187 [...] (EI mexicano, 30 de noviembre de 1994).

Al siguiente día, representantes de la Comisión Plural Binacional Mexicali-Caléxico, conformada por líderes políticos, líderes populares y ciudadanos en general, realizaron un mitin en la garita internacional y sedieron a la tarea de recolectar firmas (su meta eran reunir cien mil) en contra de la Proposición 187, para enviarlas a representantes gubernamentales deambos países.

Por otra parte, 25 obispos deCal ifornia, representados por el obispo deOakland, John Comine, firmaron un acuerdo conjunto en contra de la Ley 187 , y de rechazo a la reelección del gobernador Pete Wilson, acciones con las cuales se solidarizaron más de cien parroquias de la arquidiócesis de Tijuana (EI mexicano, 13 de octubre de 1994:6-A).

La diplomacia ciudadana, en estecaso contra la Proposición 187, trajo resultados parciales al aprobarsela suspensión dela puesta en marcha deal gunas medidas, por partede una juez federal deEstados Unidos. Posteriormente, la ley fueaprobada, pero con una serie de cambios. Y, finalmente, algunas organizaciones promovieron un amparo en las cortes federales y fue declarada anticonstitucional.

Los acercamientos entre las organizaciones defensoras de los derechos humanos de los migrantes han sido siempre en momentos coyunturales, durante los cuales se trabaja intensamente y, cuando todo pasa, sedeshacela conexión. En estesentido, Pérez Canchola, ex procurador deDerechos Humanos en Baja California, es muy atinado al manifestar que "los mejores pasos se han dado durante momentos críticos deataqueo discriminación" (Thorup, 1995:191). 
Lo interesantedeestos esfuerzos decooperación, traducidos en redes y coaliciones, es que han logrado efectuar acciones conjuntas que en un inicio fueron espontáneas, pero que van adquiriendo un carácter cada vez más permanente, como es el caso de la Posada sin Fronteras que grupos de ambos lados de la frontera real izan anual mente en el mes de diciembre, desde hace tres años, en las inmediaciones de la línea internacional entre Tijuana y San Diego.

\section{EXPERIENCIASY COALICIONESLOCALESPARA LA DEFENSA DE LOS MIGRANTES}

En el ámbito local, las ONG de Baja Cal ifornia, también han establecido redes y coaliciones al interior del propio estado, con la intención de dar apoyo a trabajadores migrantes y para protestar en contra de las violaciones a los derechos humanos en los dos lados de la frontera.

Lo interesante de sus acciones es que no sólo se han circunscrito a realizar denuncias o asumir actitudes contestatarias, sino que han tomado la iniciativa en el diseño de políticas tendientes a aminorar los estragos dela migración en los munici pios, intentando con ello influir en las agendas de discusión de las instituciones de los tres niveles de gobierno. En estesentido, también comienzan a desarrollar formas de diplomaciaciudadana.

Las respuestas locales, al igual que las transfronterizas, se establecieron principalmente para luchar contra la Proposición 187 y la Operación Guardián. Estas medidas también tuvieron repercusiones fuertes en la sociedad bajacal iforniana, y fue a partir deesas propuestas que empezaron a conformarse redes y coaliciones en las ciudades fronterizas, sobre todo en Tijuana y M exicali.

El agrupamiento entre organizaciones se reforzó, aún más, con la puesta en marcha de la segunda y tercera fase de la Operación Guardián en las fronteras San Diego-Tijuana y Mexicali-Caléxico, que recrudecieron las deportaciones de connacionales y la creciente violación de sus derechos humanos, y ante lo cual, la sociedad civil organizada comenzó a movilizarse para apoyar a los deportados. 
Una de las primeras respuestas locales antela Proposición 187, fue la Ilamada Operación Dignidad, emprendida por ciudadanos de Tijuana, que consistió en la organización de un boicot al cruce de la frontera hacia Estados Unidos los días 29 y 30 de octubre de 1994 (Bustamante, 1994a). En esa acción se unieron ciudadanos tijuanenses con actividades muy diversas, quienes se dieron a la tarea de sensibilizar a la población, por medio de diversas estrategias de comunicación, para que esos dos días se abstuvieran de realizar sus compras en el estado deCal ifornia, como una muestra de protesta por las políticas antiinmigratorias contra los migrantes mexicanos.

El Ilamado tuvo una respuesta favorable de los tijuanenses y también en todas las ciudades del estado de Baja Cal ifornia, incluso en el estado de Sonora. Los días 29 y 30 de octubre de 1994, comerciantes deChula Vista, San Diego, Caléxico y El Centro, California, así como de San Luis y Nogales, Arizona, vieron disminuidas sus ventas e, incluso en al gunas deestas localidades, I os comercios sufrieron estragos importantes, por la falta decompradores mexicanos.

Por otra parte, con la Operación Guardián, la inmigración indocumentada comenzó a desplazarse hacia las montañas y el desierto, por lo que-aunqueel operativo estadounidensefuefortalecer la vigilancia en el área San Diego-Tijuana (Ramírez; 1997) — tuvo repercusiones en las ciudades de Tecate, M exicali y San Luis Río Colorado, ya que duranteeste periodo seincrementaron las deportaciones por estos lugares, así como las muertes de al gunos indocumentados queintentaron cruzar por esas zonas hacia Estados Unidos. Lo anterior ya había sido alertado por las diversas organizaciones que se coalicionaron en la ciudad deM exicali. ${ }^{25}$

${ }^{25}$ A partir de esas fechas, las deportaciones por la garita M exicali-Cal exico se han venido incrementando vertiginosamente: en 1994, el número de deportados por Mexicali fue de 40 922; en el siguiente año, 1995, creció hasta 51 631; mientras que en 1996 llegó a 123 977, y en 1997 a 155 658. En cuanto al aumento de los riesgos para los indocumentados por el desvío dela migración hacia las zonas montañosas 
Fue precisamente en esta coyuntura cuando, en octubre de 1994, diversas ONG mexicalenses conformaron el Frente Amplio por la Dignidad (Frapad), con el objetivo de hacer frente a la política antimigrante en la región Mexicali-Caléxico, y para denunciar las múltiples violaciones a los derechos humanos que se estaban presentando en ese periodo. A parte de los centros de apoyo a los migrantes, también participaron organizaciones filantrópicas religiosas y la Subprocuraduría delos Derechos Humanos en M exicali, quecolaboró como una organización cuasi independientedel sector gubernamental .

Debido a su trabajo, este frente, posteriormente logró incorporar organizaciones civiles dela ciudad deTijuana. Las actividades quellevó a cabo consistieron en la realización de un monitoreo en la garita de Mexicali para registrar la cantidad de personas deportadas y las violaciones a los derechos humanos derivados de la Operación Guardián, así como para proporcionar al imentación, ropay en algunos casos al bergue, para los deportados.

El trabajo del frenteduró sólo los primeros tres meses; sin embargo, el impacto quetuvo en la comunidad mexicalense fue sorprendentee incluso, los medios decomunicación local es seunieron en la campaña queemprendió esa organización civil. La vida del frentefueefímeray poco a poco se fue diluyendo. ${ }^{26}$

Derivada deesta experiencialocal detrabajo conjunto, meses después se constituyó la Coalición Pro Defensa del Migrante, compuesta

\footnotetext{
y desérticas, setienequemurieron 23 mexicanos en 1994; 52 en 1995; 54 en 1996; en 1997 la cifra se elevó a 85, según datos del Instituto Nacional de Migración(INM), Estadísticas de repatriación, 1994-1997, en donde correspondió a la zona montañosa $63.4 \%$, mientras que a la zona de los desiertos $36.6 \%$.

${ }^{26}$ Cabe hacer notar que duranteel inicio delas actividades del Frapad, otras organizaciones sociales -en este caso de carácter político-, también desarrollaron actividades encaminadas hacia el mismo fin; sin embrago, sus tácticas de bloquear la garita internacional de manera transitoria, no fueron bien vistas por los miembros del frente, por lo que optaron por trabajar separados.
} 
por organizaciones dedicadas a otorgar apoyo, asesoríajurídicay ayuda material a los migrantes tales como: Centro Madre Asunta, Casa del Migrante, Casa YMCA para menores y mujeres migrantes - las tres en Tijuana - y Albergue Juvenil del Desierto y Centro de A poyo al Trabajador Migrante (en M exicali). ${ }^{27}$ La conformación de este espacio tuvo como objetivos principales la búsqueda de recursos externos, documentar casos deviolación a los derechos humanosy el intercambio de información. Sus miembros conciben su forma organizativa como coalición, pero la organización tienelas características de una pequeña red temática sobremigración. ${ }^{28}$

En el mes de abril de 1997, nuevamente resurgió en Mexicali la organización frentista que, durante 1994, habían conformado diversasorganizaciones: en esta ocasión, Ilamado FrenteA mplio Pro Defensa del Migrante (FAPDM), queaglutinó a un mayor número de organizacionesy demuy diversa actividad, incluyendo a las organizaciones de la Coal ición Pro Defensa del Migrante y a la Subprocuraduría de los Derechos Humanosy Protección Ciudadanaen Mexicali.29 Las acciones, otra vez, estuvieron encaminadas a la realización de monitoreos para

${ }^{27}$ Posteriormente, se integró el Centro de Derechos Humanos y Educación Cívica.

En torno a la conformación de redes temáticas de ONG's en el estado de Baja California, ya existen antecedentes, sobre todo de los grupos de apoyo a las mujeres, discapacitados, etcétera, sin embargo, sobre redes de apoyo a los trabajadores migratorios indocumentados, estees el antecedente más conocido.

${ }^{28}$ La conformación de esta coalición tiene las características de una pequeña red temática, en los términos que Cathryn L. Thorup (1995:170) lo plantea: "foros descentralizados para los intercambios deinformación y socialización dentro dela ONG". ${ }^{29}$ Como se ha mencionado anteriormente, la Procuraduría de los Derechos Humanos y Protección Ciudadana de Baja California, ha participado en forma autónoma al gobierno local, asumiendo en ocasiones posturas similares a las que sostienen las ONG's, aunque no es propiamente un organismo no gubernamental. En ocasiones participa en las actividades que realizan las organizaciones civiles; esto ocurreprincipalmente en la ciudad de M exicali, en donde incluso, el subprocurador participa en el FAPDM. 
registrar las violaciones de derechos humanos y para dar ayuda a los migrantes que estaban siendo afectados por la entrada en vigor de la nueva legislación migratoria estadounidense, la llamada A cta para la reforma de la inmigración ilegal y la responsabilidad migratoria (cuyo antecedente fuela Proposición 187) conocida como A cta del 96.

Como resultado de estas actividades, este nuevo frente presentó, junto con otras organizaciones en el ámbito nacional, una serie de exigencias a la Secretaría de Relaciones Exteriores. Posteriormente, realizó un monitoreo y, en su primer informe, dio a conocer los datosy conclusiones obtenidos - durante 15 días de seguimiento: del 8 al 23 de abril de 1997- a la Secretaría de Relaciones Exteriores mexicana. En él se solicitó a esta secretaría que emitiera una nota diplomática por " $\mathrm{el}$ maltrato, hacinamiento, abusos, discriminaciones y riesgos innecesarios de queson objeto los indocumentados mexicanos" (FPDM, 1997). El texto fueutilizado en la primera reunión binacional entrelos presidentes de México y Estados Unidos para tratar asuntos relacionados con la problemática migratoria.

En agosto del mismo año, el frente realizó un segundo monitoreo, pero en esta ocasión la coordinación fuemás amplia, incluyendo a varios grupos de Tijuana, Tecate y San Diego, California. ${ }^{30}$ De acuerdo con los datos que arrojó este segundo monitoreo, el Frente Amplio Pro Defensa del Migrante propuso la urgente necesidad de establecer un plan de emergencia en el que las diferentes instancias del gobierno apoyaran las iniciativas y propuestas de las organizaciones no gubernamentales pertenecientes al frente. ${ }^{31}$

\footnotetext{
${ }^{30}$ Esteinforme seenvió a la presidencia dela república al presidenteErnesto Zedillo, al coordinador general de Protección y A suntos Consulares de la Secretaría de ReIaciones Exteriores, Enrique Loaeza Tovar y al comisionado del Instituto Nacional deM igración, Fernando Solis Cámara, autoridades que contestaron al gunos delos cuestionamientos y preocupaciones que hicieron las ONG de Baja California; II Informesobreel monitoreo realizado por el FrenteA mplio Pro D efensa del M igrante, 1997. ${ }^{31}$ Frente Amplio Pro Defensa del Migrante. II Informe sobre el monitoreo real izado por el Frente A mplio Pro D efensa del M igrante, 1997.
} 
Detodas las acciones emprendidas por las redes, coaliciones y frentes de apoyo a migrantes que se han conformado en Baja California, ha sido esta última la que mayor influencia ha logrado en cuestiones de política pública, ya que tuvo buena acogida en la comunidad bajacal iforniana, y logró que autoridades gubernamentales delos tres niveles degobierno tomaran cartas en el asunto y secomprometieran a proporcionar apoyo a los migrantes deportados por la garita de Mexicali. El compromiso gubernamental seobtuvo, aunquedeforma coyuntural, en los siguientes aspectos: 1) acondicionamiento de un al bergue, para lo cual seasignaron las instal aciones del CREA-M exicali; 2) acuerdo del gobierno estatal con concesionarios transportistas, a fin de que se dispusiera de transporte urbano en horarios en que las deportaciones son más intensas; 3) acuerdo entre gobierno e instituciones de educación superior para establecer la acreditación de horas de servicio social a aquel los estudiantes que prestaran su servicio en atención a los migrantes; 4) instalación deun módulo deinformación para los migrantes por parte del gobierno federal, el cual se ubicaría en la zona de deportación, y el personal encargado de atenderlo sería capacitado por el Consulado Mexicano y el Instituto Nacional de Migración de la Secretaría de Gobernación; 5) dotación de, cuando menos, 50 bol etos detransporteforáneo al día, para lo cual el gobierno estatal concertaría con las empresas concesionarias; 6) apoyos económicos por parte del gobierno del estado a las ONG que presten atención a migrantes, especial mentea niños y mujeres. ${ }^{32}$

Conseguir que las autoridades gubernamentales realizaran estas acciones, fue producto de varias reuniones previas entre los organismos civiles y representantes de gobierno, en las cuales se analizó el impacto delanuevaley deinmigración en Californiay sus repercusiones

\footnotetext{
32 Todo los datos fueron tomados de: "A poyo a deportados. Concertan plan emergentedeacción", El mexicano, 23 deabril de 1997, p. 1-A, elnformedel FrenteA mplio Pro D efensa del M igrante, 1997.
} 
en el número de personas que estaban siendo deportadas por las fronteras de Baja California. Para llevar a cabo un seguimiento de los acuerdos y compromisos tomados, se integró un grupo operativo de los tres niveles de gobierno y los representantes de las ONG. Los compromisos secumplieron parcial mente, puesto quela visión delos representantes gubernamental es fue concebir el problema migratorio demanera coyuntural, y pasada la emergencia, las autoridades dieron por concluidos los acuerdos contraídos. ${ }^{33}$

Sin duda, "sentar" en una mi sma mesaa los tres sectores de gobierno fue una experiencia muy positiva para las ONG. Sin embargo, su actuación no se quedó ahí, pues continuaron proponiendo medidas que permitieran aminorar la problemática de los migrantes, no sólo en el corto plazo. Hicieron propuestas para atender el problema demanera preventiva y más organizada, entre las que destaca la creación de un fideicomiso para real izar acciones integrales en favor delos migrantes que estaban siendo deportados, que contemplara programas de capacitación y educación para el trabajo, bolsa de trabajo, programas de retorno a sus lugares de origen, la creación de un sistema de localización de migrantes extraviados, apoyo económico a los grupos que brindan asistencia a los migrantes, comunicación con los estados de origen para establecer convenios, etcétera. El fideicomiso, según la propuesta, sería administrado por las propias ONG . ${ }^{34}$

La visión que presentaron las ONG, en esta propuesta, sealejaba de las soluciones jurídico-policiacas que vienen desarrollando las instancias gubernamentales para hacerle frente a los problemas suscitados por la deportación masiva de connacionales. Las ONG entendieron la situación como un problema social, al que habría que darle un tratamiento en el mismo sentido.

\footnotetext{
33 Únicamentecontinuaron prestando los servicios detransportehacia la Central de Autobuses y el apoyo económico a las ONG.

${ }^{34}$ Frente A mplio Pro Defensa del Migrante, 1997.
} 
La posibilidad de influir en las políticas públicas en el estado de Baja California desdelas ONG, especialmenteen materia demigración, al parecer hoy, más que nunca, se presenta favorable.

\section{TRESDIMENSIONESDE LA PARTICIPACIÓN DE LASORGANIZACIONES CIUDADANASDE BAJA CALIFORNIA}

La participación de las ONG de Baja California, desde nuestra perspectiva, se pueden ubicar en tres dimensiones según el espacio quepretenden alcanzar:

\section{ACTIVISM O REGIONAL}

Graciasal trabajo querealizan, las oNG deapoyo al migrantelocalizadas en BajaCal ifornia han empezado a tener presencia en diferentesámbitos de la política pública local. De ser organizaciones con objetivos meramente asistenciales, pasaron a constituir grupos con fuerte peso en la opinión pública regional einstancias gubernamentales, tanto del nivel municipal como estatal. De igual manera, ya han establecido contactos sólidos con grupos similares en el área de California, para hacer frentea una problemática común: el mal trato delas autoridades de migración estadounidenses contra los migrantes y el racismo creciente contra los mexicanos.

La participación conjunta quehan emprendido las redes y coaliciones de organizaciones no gubernamentales de Tijuana, Mexicali y San Diego, y su inserción dentro dela vida pública dela región territorial que comparten, nos permite ubicarlas como parte de un proceso de regionalismo transfronterizo, pues de acuerdo con la propuesta de Duchacek, el concepto debe ser entendido como la suma de varias redes de comunicación formales e informales y mecanismos de resolución de problemas, ante problemáticas presentadas por la contigüidad, y que requieren ser abordadas por instancias bilaterales (Duchacek, 1986: 14). 
Recientemente, organizaciones de Tijuana y San Diego colocaron en la ciudad de Tijuana un gran letrero permanente donde anuncian, cada semana, el número de muertes de mexicanos indocumentados que cruzan hacia Estados Unidos. También, a iniciativa de al gunas ONG de Tijuana se ha creado una instancia municipal que realizará, junto con las ONG acciones en favor de los migrantes que llegan a esa ciudad. ${ }^{35}$

Los contactos transfronterizos deoNG, si bien no han llegado al grado deplantear mecanismos profundos desolución, sí han realizado líneas de acción que van en ese sentido y han logrado establecer lazos de comunicación de tipo informal, encaminadas a conexiones más formales. Sus actividades se desarrollan en comunidades que comparten un espacio territorial: Ia frontera entre California y Baja California, donde se origina un problema de derechos humanos que involucra a actores de ambos lados.

\section{INTENTOSDE PARTICIPACIÓN A NIVEL NACIONAL}

La presencia de las ONG de Baja California poco a poco ha ido trascendiendo la esfera local. Su trabajo constante de apoyo a los migrantes y en otras problemáticas, les havalido para quesean tomadas en cuenta en la realización de algunos análisis y diagnósticos de instancias nacionales. Ejemplo de esta situación son las invitaciones que han recibido para participar en eventos de carácter federal como los foros sobre migración, organizados por la Comisión de A suntos Fronterizos del Congreso de la Unión, para tratar el asunto de la migración hacia Estados Unidos.

Por su calidad moral y decredibilidad lograda, la Comisión Nacional de Derechos Humanos también ha solicitado la cooperación de estas

35 Entrevista a Raúl Ramírez, director del Centro de Apoyo a los Migrantes de Tijuana. 
redes deapoyo, para real izar diagnósticos acerca dela situación delos derechos humanos de los migrantes, específicamente la situación de niñosy mujeres.

Organizaciones con presencia nacional, como la Academia M exicana de Derechos Humanos, han recurrido constantemente a las organizaciones bajacalifornianas para fundamentar sus denuncias ante diversos foros internacionales.

Otro tipo de acciones que intentan influir en la política pública a escala nacional, son aquellos documentos o cartas enviadas a instancias gubernamentales federales a través de las cuales se hacen denuncias, señalamientos y/ o propuestas sobreasuntos quetienen quever con la problemática delos trabajadores migratorios.

Las organizaciones no gubernamentales deBaja California también han recurrido a esta clase de expresiones; ejemplo de ello es la carta que, en abril de 1997, enviaron organismos y ciudadanos mexical enses al presidente de la república, Ernesto Zedillo, en la que demandan, entre otras cosas: "una enérgica nota diplomática, en la cual se exija al gobierno norteamericano quecumpla con la $\mathrm{D}$ eclaración universal delos derechos humanos, estipulada en la onu y firmada por ambos países [...] Que se implemente un plan emergente integral, de apoyo a los migrantes en todas las ciudades fronterizas mexicanas". ${ }^{36}$

Antela crecienteparticipación delas ONG en la esfera nacional, cabe señalar queal gunas han comenzado a representar el papel devoceras de la sociedad civil ante instancias gubernamentales nacionales e incluso internacionales, desplazando, en al gunos casos, a los partidos políticos como representantes de diversos sectores sociales. Tal es el caso de la Coalición Pro Defensa del Migrante, que ha tomado la

36 Información obtenida de la "Carta al señor presidente de los Estados Unidos Mexicanos de parte de organizaciones y ciudadanos de Mexicali, B.C.", 28 de abril de 1997, Mexicali, B.C. 
iniciativa de visitar a los representantes del Congreso, a la Secretaría deRelaciones Exteriores y otras dependencias gubernamentales, para plantearles la situación que se percibe en el estado fronterizo de Baja California sobreel fenómeno migratorio. ${ }^{37}$

Recientemente, también la Coalición Pro Defensa del Migranteinició una gira por los estados de Michoacán, Guanajuato, Jalisco, A guascalientes, Zacatecas y Chihuahua, considerados como expulsores de trabajadores migrantes, con los objetivos de: 1) dar a conocer las organizaciones que brindan apoyo y atención a los migrantes en algunos puntos fronterizos, sobretodo los dela coalición; y 2) distribuir 5000 trípticos y carteles en las zonas de origen de los migrantes, y establecer una campaña de información sobre las zonas de riesgos de crucemigratorio, así como los posi bles apoyos quelas organizaciones de la zona fronteriza de Baja California-California pueden brindar a los migrantes. ${ }^{38}$

Entrelas propuestas más importantes que hicieron las ONG de Baja California a las organizaciones de aquellas entidades, está la creación de una red informal más amplia entre las organizaciones del norte y las de los estados deorigen de losinmigrantes, detal forma quepermita establecer vínculos de información eintercambio (Villaseñor y Maza, 1997:30-36).

A unque la influencia en la toma de decisiones gubernamentales a escala nacional es parcialmente reducida, las coaliciones y redes de organizaciones de derechos humanos han venido "alzando la voz" , y han logrado ganar presencia en espacios oficiales, para plantear sus

\footnotetext{
${ }^{37} \mathrm{Al}$ respecto hay al gunas cartas que la Coalición ha enviado junto con la Red Sin Fronteras a esas instituciones; por ejemplo: "Carta al señor presidente de los Estados Unidos Mexicanos de parte deorganizaciones y ciudadanos de Mexicali, B.C.", 28 deabril de 1997, Mexicali, B.C. "Oficio dirigido al Congreso dela Unión”, marzo de 1997; "Peticiones de organismos sociales a la Secretaría de Relaciones Exteriores", abril de 1997.

38 Informe de la Coalición Pro defensa del Migrante durante,1997, mimeo.
} 
propuestas e iniciativas; prueba de ello son las invitaciones de las autoridades de la Secretaría de Relaciones Exteriores a los grupos defensores de los migrantes de Baja California.

PASOS HACIA LA ESCENA INTERNACIONAL

Aunque las organizaciones ciudadanas en Baja California han dirigido sus esfuerzos a realizar un trabajo primordialmentelocal y nacional, en fechas recientes estos grupos han intentado establecer contactos fuera del país, a fin dehacerse presentes en otros espacios en los cuales puedan dar a conocer la situación respecto a la violación delos derechos humanos de los migrantes que son detenidos y deportados por estas fronteras.

En este sentido, las organizaciones localizadas en Tijuana son las más activas; por ejemplo, representantes de la Casa del Migrantehan encabezado diversas iniciativas para enviar misivas a personajes dela política internacional con la intención de denunciar la sistemática violación a los derechos humanos por parte de las autoridades norteamericanas de Inmigración. Una acción al respecto es la carta que fue enviada a la señora $\mathrm{H}$ illary Clinton, esposa del presidente de Estados Unidos, en la cual diversos organismos, instituciones y personas dela entidad, leexpresan que "en su cal idad demujer, esposa y madre de familia intervenga para frenar las políticas antimigratorias quecada vez sehan endurecido más en la administración desu esposo Bill Clinton y queestán afectando a millones de personas entre los que seencuentran mujeres y niños" (Proceso, 4 demayo de 1997). Con este tipo de manifestaciones, las ONG deBaja Cal ifornia intentan expresarse más allá del ámbito local, con la intención de ejercer presión para que los gobiernos correspondientes pongan más atención a la problemática migratoria.

Además de realizar esta dlase dellamados, las ONG bajacal ifornianas se han dedicado a documentar casos de violaciones a los derechos humanos de los migrantes, para presentarlos ante instancias internacionales. Un caso que integró la Procuraduría de los Derechos Humanos, con la anuencia de un numeroso grupo deoN G locales, para 
presentarlo ante la Comisión Interamericana de Derechos Humanos, fue 1 de 60 trabajadores que fueron detenidos en Caldwell, Idaho, y deportados por la garita de M exicali. En este caso, la demanda iba dirigida contra los Estados Unidos; además, en este documento se expresaba la complicidad de la empresa fabricante de casas móviles Kit (lugar de trabajo de las 60 personas), en la detención de los indocumentados. ${ }^{39}$

Desafortunadamente, por cuestiones técnicas, la reclamación no llegó a formalizarse ante la instancia internacional; sin embargo, constituyó un esfuerzo importante de coordinación y un avance en la lucha por los derechos de los migrantes.

Por otro lado, al gunos representantes de las ONG locales asisten regularmente a eventos y foros de carácter internacional como la conferencia quese realiza el 5 demayo decada año en la Universidad de Chicago, en donde se discuten y analizan temas migratorios, y las ONG's dan a conocer sus actividades, presentando informes sobre la situación queguardan los derechos humanos de los migrantes anteel trato de las autoridades de migración estadounidenses y mexicanas. También han participado en eventos similares organizados en varias partes del estado de California.

Las ONG fronterizas deapoyo al osmigrantes han realizado contactos (además de los establecidos con grupos de San Diego) con organizaciones de derechos humanos establecidas en varias partes del mundo como Amnistía Internacional, Human Rights Watch/ Américas, y

\footnotetext{
${ }^{39}$ Estos datos fueron obtenidos de una copia de la denuncia elaborada para la Comisión Interamericana de Derechos Humanos. Los organismos firmantes son: Albergue Juvenil del Desierto; Centro de Derechos Humanos y Educación Cívica; Educación y Servicios Comunitarios A.C.; Escuela Hogar Buen Pastor, A .C.; Centro de A poyo al Trabajador Migrante, A.C.; Grupo Feminista Alaide Foppa; A sociación de Scouts de México; A sociación Mexicana para la Superación Integral de la Familia, A.C.; CELSIME; La Casita; ComitéCívico de Divulgación Ecológica; Sección 2 del SNTE, y Procuraduría de los Derechos Humanosy Protección Ciudadana del Estado de Baja California, así como una lista de personas quefirman a título individual.
} 
Lawyers Committee for Human Rights. En fechas recientes, Amnistía Internacional ha establecido contacto con los organismos defensores de derechos de los migrantes en Tijuana, para atender el caso de los indocumentados mexicanos hacia Estados Unidos.

La red latinoamericana Sin Fronteras, organismo que aglutina a organizaciones queluchan por los trabajadores migrantes en México y Centroamérica, también seha acercado alas ONG locales, principalmente de Mexicali, para documentar casos de violaciones de derechos humanos. Las relaciones se han estrechado a tal grado, que ya participan juntas en los encuentros trilaterales que los gobiernos del TLC efectúan cada año, ocupando ya un espacio en la agenda que los gobiernos tienen establecidos.

Este tipo de relaciones permite a las on locales tener las puertas abiertas para denunciar violaciones de derechos humanosen el ámbito internacional. En marzo de 1997, en la II Conferencia Regional sobre Migración, con sedeen la ciudad dePanamá, las organizaciones deBaja California lograron colocar sus propuestas en el documento III Resolución de organismos no gubernamentales sobre el tema del fenómeno migratorio, quepresentó la Red Informal sobre Migración. ${ }^{40}$

Estas acciones y vínculos de carácter internacional, podrían considerarse acercamientos a formas de microdiplomacia de oNG (en el mismo sentido que lo hacen los gobiernos subnacionales), aunque muy limitados. Es decir, siguiendo los planteamientos de Duchacek, se encuentra una relación con la microdiplomacia, ya que, efectivamente, se dan procesos y redes a través de las cuales los organismos civiles buscan contactos y establecen convenios de cooperación a escala global (Duchacek, 1986), ${ }^{41}$ con la intención de

40 III Resolución de organismos no gubernamentales sobre el tema del fenómeno migratorio, Plan de acción, Red Informal de Organizaciones no Gubernamentales, 20 de marzo de 1997. Entrevista a Blanca Villaseñor, participante del evento.

${ }^{41}$ Los actores en el concepto de mocrodiplomacia global definido por Duchacek, son los gobiernos locales o subnacionales, cuyo interés primordial es promocionar sus localidades. 
promocionar la defensa delos derechos humanos. En el mismo sentido, constituyen actividades de trasnacionalización de la participación cívica, referida por Cathryn Thorup en su trabajo sobre diplomacia ciudadana. Al respecto, la autora menciona que: "Las organizaciones no gubernamentales (ONG), tanto locales como nacionales, están haciendo sentir su presencia de la manera más creciente en materia internacional, en forma cada vez más concertada con grupos similares de otros países"(Thorup, 1995: 155).

\section{ALGUNASCONSIDERACIONESFINALES}

A nte las acciones y planteamientos que las organizaciones no gubernamentales han desarrollado y que en este texto se han descrito, podemos resumir algunas conclusiones y consideraciones:

La problemática común queseorigina en la región transfronteriza, en donde los diferentes gobiernos no tienen la suficiente voluntad de actuar, las organizaciones no gubernamentales se presentan como una alternativa real (aunque todavía limitada) para dar respuesta a los asuntos que han rebasado la capacidad de las instituciones gubernamentales. Es precisamente en el ámbito de la lucha por la defensa de los trabajadores migratorios indocumentados, donde las ONG locales de Baja California tienen las mayores posibilidades de incidir en las agendas de discusión y en las políticas públicas de los gobiernos involucrados.

La preocupación por la defensa de los migrantes que llegan a esta región, ha llevado a las ON G locales a transitar del asistencial ismo a la denuncia pública, como formadepresión para quelosgobiernostomen medidas en defensa de los derechos humanos. Aunque en forma limitada, sus peticiones han tenido pequeños logros en la escala local que han sentado precedentes dignos de tomarse en cuenta.

Algunas organizaciones no gubernamentales han demostrado su gran capacidad de organización y convocatoria ante diversos actores para llevar a cabo acciones a diferentes escalas. Su desarrollo en el nivel local, la presencia que poco a poco van adquiriendo el nivel nacional y su interés por insertarse en la escena internacional, les otorga 
un gran potencial como interlocutoras dela sociedad civil y, sobretodo, de aquéllos que no tienen voz, como es el caso de los migrantes indocumentados que cruzan hacia los Estados Unidos.

La aprobación de la Proposición 187 mostró, quizá, la falta de influencia que aún tienen los latinos en California, pero la gran movilización que encabezaron organizaciones no gubernamentales para protestar en contra de esta iniciativa y la Operación Guardián, nos indica la capacidad de convocatoria, de respuesta y de concientización que han adquirido estos grupos en problemáticas domésticasy deorden internacional, no sólo en California, sino en todos los Estados Unidos.

Sin duda, la diplomacia ciudadana está cobrando gran importancia en la esfera dela política pública en todos losámbitos, por lo queen un plazo no muy lejano, los gobiernos no podrán soslayar más la importancia de los grupos ciudadanos en la toma de decisiones. En ese tenor, las ONG representan importantes canales de consulta para establecer nuevas relaciones de cooperación bilaterales, tanto en el ámbito local, nacional e internacional. Y con sus voces, quizá lentas pero insistentes y firmes, presentan un gran potencial de influencia para quelos gobiernos tomen decisiones de política pública con "rostros máshumanitarios".

Algunos retos, tanto para las ONG como para las redes y coaliciones que ellas han conformado local mente y a nivel transfronterizo, están en la búsqueda de vínculos y conexiones más duraderos, quelas lleven a realizar planteamientos desdeespacios más formales, así como evitar la cooptación delos gobiernos y los partidos políticos. 


\section{BIBLIOGRAFÍA}

Armendares, Pedro Enrique(1994). “El año delas ONG's, La jornada, 24 de septiembrede 1994. Suplemento dex aniversario, México.

Avendaño, Rosa María (1996). "Las ONG's en Baja California: un acercamiento al trabajo querealizan", en D ebatedemocrática, núm. 2, revista del IFE, Delegación Baja California.

Berlié, Emilio Carlos (1994). Declaración publicada por el periódico EI mexicano, 13 de octubre de 1994.

Bobbio Norberto. 1981. Diccionario depolítica, México, Siglo XXI.

Bustamante, Jorge A. (1994a). "Frontera norte. Los toros del jaral". Excélsior, 31 de octubre.

1994b. “Frontera norte. Tijuanenses en acción". 3 de octubre.

Eernea, Michael (1989). O rganismos no gubernamentales y desar rollo local, documentos para la discusión del Banco M undial, Washington.

Clement, Norris C., Mathew B. Herndon y Gonzalo López (1996). "Responding to the Economic Crisis in San Diego-Tijuana", mimeo, San Diego California.

Cortez Ruiz, Carlos (1994). " Las organizaciones no gubernamentales: un nuevo actor social", Revista mexicana de sociología, IIS-UNAM, núm. 2, México.

Connolly, P. et al. (1991). Cambiar de casa pero no debarrio. Estudios sobre la construcción de la ciudad de México, CENVI/ UAMAzcapotzalco, México.

Coulumb, René(1997). “ONG y políticas sociales: una problematización desde el hábitat popular", R evista mexicana de sociología, vol. 59, núm. 2, abril-junio.

Driscoll, Bárbara (1996). “Laemigración mexicanaa losEstados Unidos: un dilema para México". El cotidiano, núm. 77, julio-agosto, Universidad Autónoma Metropolitana.

Duchacek, I vo D. (1986). "International Competence of Subnational Governments: Borderlands and Beyond", en Martínez, Oscar J. (ed). A cross Boundaries. Transborder Interaction in Comparative Perspective, Texas Western Press, EL Paso, Texas. 
Equipo Pueblo (1997). “Equipo Pueblo, sociedad civil, actor de gobernabilidad: la propuesta deEquipo Pueblo", memoria, 136, mimeo, en Coulumb, René, 1997. “ONG y políticas sociales: una problematización desdeel hábitat popular", en: R evista mexicana de sociología, vol. 59, núm. 2, abril-junio de 1997.

Foro de A poyo Mutuo (1985). O rganismos no gubernamentales: D efinición, presencia y perspectivas, México.

Ghils, Paul (1992). “La sociedad civil internacional: las organizaciones internacional es no gubernamental es en el sistema internacional", Revista internacional de ciencias sociales, UNESCO, núm. 133.

Gordon Rapoport, Sara (1997). “La cultura política delas organizaciones no gubernamentales en México". Revista mexicana de sociol ogía, vol. 59, núm. 1, enero-marzo.

Heredia Zubieta, Carlos y Ricardo Hernández Sánchez (1996). La diplomacia ciudadana en la era de la globalización: un punto de vista desdeM éxico, DECA, Equipo Pueblo A.C.

Hernández, Sergio (1996). "Los efectos de la globalización en los partidos políticos y en los procesos el ectorales local es", en Debate democrático, núm. 2, revista del IFE, Delegación Baja California. Koulish, RobertE. y John Robert Warren (1995). “Violations of Human and Civil Rights by USImmigration A uthorities in a South Texas Border Community", en Río Bravo, vol. IV, núm. 1-2, The University of Texas-Pan American Press, Texas.

Moreno Mena, José A . (1996a). “Las organizaciones no gubernamentales en M éxico" en Semillero, año 4, núm. 13, enero-marzo, UABC.

_ 1996b. "Las organizaciones no gubernamentales: un interlocutor dela sociedad civil", en D ebatedemocrático, IFE, año 1, núm. 2, marzo, Mexicali, B.C.

Páez Delgado, Raúl (1997). M ercado global del atún y embargo estadounidense (un caso de neoproteccionismo comercial), edición de la Semarnap y el Congreso dela Unión, México.

Pérez Canchola, José Luis (1997). “La inmoral política migratoria de los Estados Unidos", en "Derechos humanos y ciudadanía”, La Jornada, suplemento mensual, núm. 5, febrero de 1997. 
Ramírez, Raúl (1997). “La nueva política norteamericana en materia deinmigración. Antecedentes, alcancesy consecuencias", Societas, Revista del Colegio de Sociólogos de B.C., núm. 4, octubre.

Real Academia de la Lengua Española (1983). D iccionario de la lengua española, Madrid.

Thorup, Cathryn L. (1995). “Diplomacia ciudadana, redes y coaliciones transfronterizas en América del Norte: nuevos diseños organizativos", en Foro internacional, Vol. XXXV, núm. 2, abril-junio, El Colegio de México. México, D.F.

Tocqueville, Alexis de (1979). La democracia en A mérica, FCE, México, 3ra. reimp.

Villaseñor, Blanca y Enrique Maza (1997). "Síntesis y conclusiones de un recorrido por los estados de Michoacán, Guanajuato, Jalisco, Aguascalientes, Zacatecas y Chiapas". Societas, del Colegio Estatal deSociólogos deBaja California, núm. 5.

Viñuelas Víctor y Dominic Wyatt (1997). “Las ONG's: ni heroínas ni villanas", En pie de paz, núm. 44, Barcelona, España.

\section{HEMEROGRÁFICA}

Cambio, periódico local, ejemplarespublicadosentreed 1y 31 deoctubre de 1994, Tijuana. B.C.

El mexicano, periódico local, ejemplarespublicados del 1al 31 deoctubre de 1994, y el 23 de abril de 1997.

La opinión, periódico local, ejemplarespublicadosdel 1al 31 deoctubre de 1994, Los Angeles, California.

Proceso, semanario deinformación y análisis, núm. 1070, 4 demayo de 1997, México, D.F.

\section{DOCUMENTO INÉDITOS}

Memorándum de entendimiento sobre protección consular de nacionales deEstados Unidosy deMéxico. México, 1996. Docto. dela Secretaría de Relaciones Exteriores, mimeo. 
Procedimientos para la repatriación segura y ordenada deNacionales

Mexicanos. San Diego CA. , diciembre de 1997.

"I Carta al Señor presidentedelos Estados Unidos M exicanos de parte

de organizaciones y ciudadanos de Mexicali, B.C." , 28 de abril de 1997, Mexicali, B.C.

Coalición Pro Defensa del Migrantey Sin fronteras. "Oficio dirigido al

Congreso de la Unión", marzo de 1997

Coalición Pro Defensa del Migrante, "Peticiones deorganismos sociales

a la Secretaría de Relaciones Exteriores, abril de 1997.

Declaración conjunta de las organizaciones no gubernamentales ante IallI Conferencia Regional sobre Migración, Otawa, Canadá, 26 de febrero de 1998.

"III Resolución de organismos no gubernamentales sobre el tema del fenómeno migratorio"; plan de acción, Red Informal de Organizaciones no gubernamentales, 20 de marzo de 1997.

IV Resolución de organismos no gubernamentales sobre el tema del fenómeno migratorio", reunión técnica dela conferencia regional sobre migración, San José de Costa Rica, 13 y 14 de noviembre de 1997.

Informe de la Coalición Pro Defensa del Migrante durante 1997, Mexicali. B.C., mimeo.

"Network Mexico-USA", Advocates. An iniciative of the Herartlan Alliancefor Human Needsand Human Rights. Chicago, IL.,1997. mimeo.

FrenteA mplio por la Dignidad, “Informedel monitoreo real izado por el Frente Amplio por la Dignidad', documento no publicado, Mexicali, B.C., noviembre de 1994.

FrenteAmplio Pro Defensa del Migrante(FPDM). “Informey condlusiones del II monitoreo realizado por el FrenteA mplio Pro Defensa del Migrante", documento no publicado, M exicali, B.C., abril de 1997.

_ "Denuncia elaborada para la Comisión I nteramericana de Derechos Humanos por organizaciones y ciudadanos de Mexicali", manuscrito no publicado, Mexicali, B.C., abril de 1997. 